\title{
Determinants of Regioselectivity and Chemoselectivity in Fosfomycin Resistance Protein FosA from QM/MM Calculations
}

\author{
Rong-Zhen Liao and Walter Thiel* \\ Max-Planck-Institut für Kohlenforschung, Kaiser-Wilhelm-Platz 1, D-45470, Mülheim an der Ruhr, Germany \\ Supporting Information
}

ABSTRACT: FosA is a manganese-dependent enzyme that utilizes a $\mathrm{Mn}^{2+}$ ion to catalyze the inactivation of the fosfomycin antibiotic by glutathione (GSH) addition. We report a theoretical study on the catalytic mechanism and the factors governing the regioselectivity and chemoselectivity of FosA. Density functional theory (DFT) calculations on the uncatalyzed reaction give high barriers and almost no regioselectivity even when adding two water molecules to assist the proton transfer. According to quantum mechanics/molecular mechanics (QM/MM) calculations on the full solvated protein, the enzyme-catalyzed glutathione addition reaction involves two major chemical steps that both proceed in the sextet state: proton transfer from the

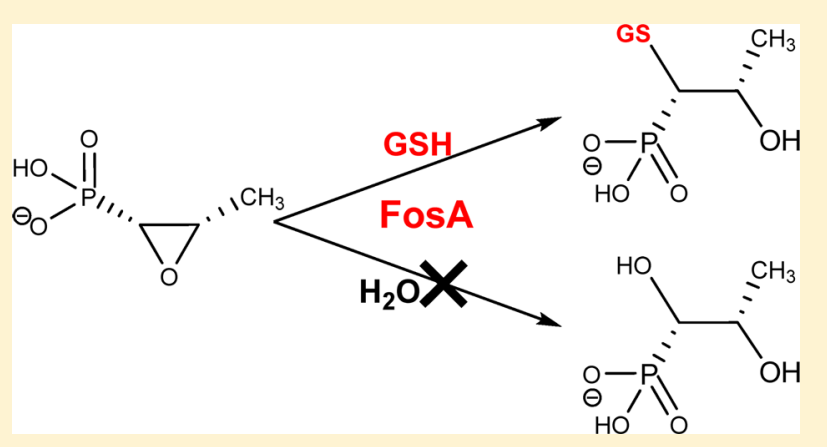
GSH thiol group to the Tyr39 anion and nucleophilic attack by the GSH thiolate leading to epoxide ring-opening. The second step is rate-limiting and is facilitated by the presence of the high-spin $\mathrm{Mn}^{2+}$ ion that functions as a Lewis acid and stabilizes the leaving oxyanion through direct coordination. The barrier for $\mathrm{C} 1$ attack is computed to be $8.9 \mathrm{kcal} / \mathrm{mol}$ lower than that for C2 attack, in agreement with the experimentally observed regioselectivity of the enzyme. Further QM/MM calculations on the alternative water attack predict a concerted mechanism for this reaction, where the deprotonation of water, nucleophilic attack, and epoxide ring-opening take place via the same transition state. The calculated barrier is $8.3 \mathrm{kcal} / \mathrm{mol}$ higher than that for GSH attack, in line with the observed chemoselectivity of the enzyme, which manages to catalyze the addition of GSH in the presence of water molecules around its active site. The catalytic efficiency, regioselectivity, and chemoselectivity of FosA are rationalized in terms of the influence of the active-site protein environment and the different stabilization of the distorted substrates in the relevant transition states.

\section{INTRODUCTION}

The natural product fosfomycin [(1R,2S)-epoxypropylphosphonic acid, Scheme 1], which is synthesized by strains of bacteria Streptomyces, possesses antibacterial activity toward both Gram-positive and Gram-negative microorganisms. ${ }^{1,2}$ It irreversibly inhibits MurA (UDP- $N$-acetylglucosamine-3-enolpyruvyltransferase), an important enzyme in bacterial cell wall biosynthesis (Scheme 1). ${ }^{3}$ This inhibition is achieved through alkylation of an active-site cysteine residue, which performs a nucleophilic attack on the $\mathrm{C} 2$ atom of fosfomycin. ${ }^{3-5}$

Fosfomycin resistance proteins perform enzymatic modification and inactivation of the antibiotic to lower the clinical efficacy and therefore serve as potential targets for inhibitor design. ${ }^{6-8}$ Three classes of such proteins have been identified on the basis of sequence identity and type of catalyzed reaction. FosA is a $\mathrm{Mn}^{2+}$-dependent enzyme that catalyzes the ringopening of the epoxide moiety of fosfomycin by regiospecific addition of the tripeptide glutathione (GSH) to $\mathrm{C} 1$ of the substrate (Scheme 1). ${ }^{9-13}$ FosB utilizes a $\mathrm{Mg}^{2+}$ ion to promote the addition of L-cysteine to the epoxide ring of fosfomycin. ${ }^{14}$ FosX has a $\mathrm{Mn}^{2+}$ ion in the active site and is involved in the hydration of fosfomycin furnishing a diol product. ${ }^{15-17}$ Amino acid sequence comparisons have demonstrated that these three enzymes are members of the vicinal oxygen chelate (VOC) superfamily of metalloenzymes. ${ }^{18}$ The structural hallmark of this superfamily is a paired $\beta \alpha \beta \beta \beta$ motif that offers coordination sites to the metal, which in turn help substrate binding through direct coordination. ${ }^{18}$

The X-ray structures of FosA from Pseudomonas aerugino$s a^{13,19}$ and transposon $\operatorname{Tn} 2921^{20}$ have been solved. They show a dimeric architecture with a mononuclear manganese center in each active site. In the structure of FosA in complex with fosfomycin, $\mathrm{Mn}^{2+}$ is ligated to His7 of chain A, His64 and Glu110 of chain B, oxirane oxygen, and one phosphonate oxygen of the substrate. ${ }^{13}$ The metal is pentacoordinated in a trigonal-bipyramidal fashion, with the glutamate oxygen and the oxirane oxygen in the axial positions. EPR studies of FosA showed that the $\mathrm{Mn}^{2+}$ ion $\left(3 \mathrm{~d}^{5}\right)$ is in the high-spin sextet state. $^{21,22}$ Interestingly, a $\mathrm{K}^{+}$ion was found in a loop close to the active site, consistent with the important role of $\mathrm{K}^{+}$for enzyme activity. ${ }^{11}$ Lys90, Ser94, Tyr100, and Arg119 donate hydrogen bonds to the phosphonate oxygen atoms and thus

Received: January 9, 2013

Published: January 15, 2013 
Scheme 1. Transformations of Fosfomycin by Different Enzymes

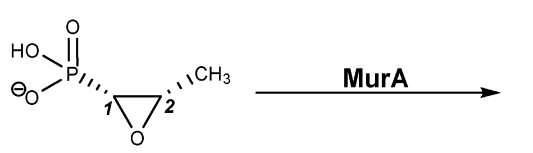<smiles>C[C@@H](S[Ga])[C@@H](O)P(=O)([O-])O</smiles>

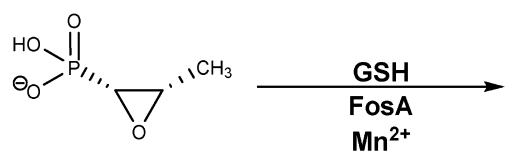<smiles>C[C@@H](O)C([AsH3])P(=O)([O-])O</smiles>

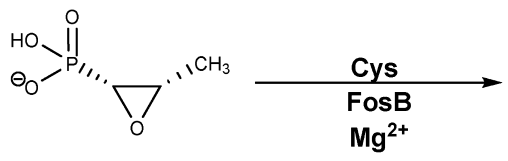

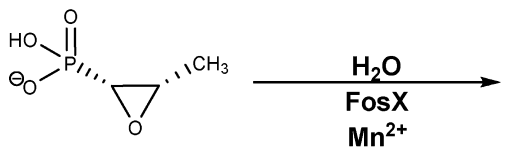

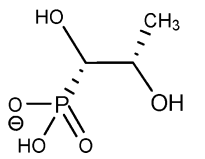

help substrate binding. Mutations of these residues lead to loss of activity. ${ }^{23}$

On the basis of docking studies, it was proposed that the thiol group of GSH is hydrogen-bonded to Tyr39, and the terminal glutamic acid forms hydrogen bonds to Lys 90 and Arg93. ${ }^{24}$ Mutagenesis studies gave a 13-fold reduction of activity for $\mathrm{Y} 39 \mathrm{~F}$ and suggested that Tyr39 functions as a general base to abstract a proton from GSH during the reaction. ${ }^{24}$ In order to do so, Tyr39 should be deprotonated, with the anion being stabilized by hydrogen bonding to the nearby Arg119 residue. The use of tyrosine/tyrosinate as acid/ base has also been proposed for many other enzymes, for example, epoxide hydrolase, ${ }^{25-28}$ haloalcohol dehalogenase, ${ }^{29,30}$ nitrile hydratase, ${ }^{31}$ alanine racemase, ${ }^{32}$ dehydroquinase, ${ }^{33}$ and glycoside hydrolase BglT. ${ }^{34}$ During the nucleophilic attack, the $\mathrm{Mn}^{2+}$ ion provides electrostatic stabilization to the oxyanion and assists the ring-opening. One of the important puzzles of this enzymatic reaction is the observed regioselectivity: GSH exclusively attacks $\mathrm{C} 1$ in FosA, ${ }^{10}$ while the uncatalyzed reaction is essentially unselective (yield of $40 \%$ on $\mathrm{Cl}$ and $60 \%$ on

C2). ${ }^{11}$ Another interesting aspect is that FosA does not employ a water molecule to perform the nucleophilic attack, as in the case of FosX, ${ }^{15-17}$ even though the enzyme has a wateraccessible open pocket, implying that FosA is chemoselective.

The understanding of selectivity in enzymatic epoxide transformations is expected to help in the design of new epoxide hydrolases with modified selectivity. Quantum mechanics (QM) and quantum mechanics/molecular mechanics (QM/MM) calculations have been used to elucidate the mechanism and to explain the regioselectivity of a number of epoxidases. $^{35-41}$ In the present paper, we report density functional theory (DFT) and QM/MM studies on the reaction mechanism of FosA, with particular focus on the origin of regioselectivity and chemoselectivity. The uncatalyzed reaction with methanethiol as a model compound for GSH assisted by two water molecules was studied by DFT and double-hybrid DFT methods, in order to provide a reference for assessing the rate enhancement of the enzyme. In addition, QM/MM calculations were carried out for the whole solvated enzyme with both GSH and water as substrates.

\section{METHODS}

2.1. QM Calculations of the Uncatalyzed Reaction. The QM calculations for the uncatalyzed reaction were done using the Gaussian09 ${ }^{42}$ program and the B3LYP ${ }^{43}$ functional. For geometry optimizations, the def2-SVP ${ }^{44}$ basis set was employed for all elements. Based on the optimized geometries, singlepoint calculations were carried out using the larger def2$\mathrm{TZVPP}^{44}$ basis set for all atoms. The stationary points were confirmed as minima (zero imaginary frequencies) or transition states (TS, only one imaginary frequency) by analytic frequency calculations at the same level of theory as applied in the geometry optimizations. The reaction pathways were subjected to intrinsic reaction coordinate (IRC) ${ }^{45,46}$ analysis in order to trace their paths and to confirm that the optimized TS structures connect two relevant minima. Solvation effects were examined by performing single-point calculations at the optimized structures using the $\mathrm{SMD}^{47}$ continuum solvation model for water.

To check the sensitivity of the results to the choice of functional, further single-point calculations were done using the $\mathrm{M}^{4} 6^{48}$ and $\omega \mathrm{B} 7 \mathrm{X}^{49}$ functionals, as well as the double-hybrid B2PLYP ${ }^{50}$ functional. The reported B3LYP energies are Gibbs

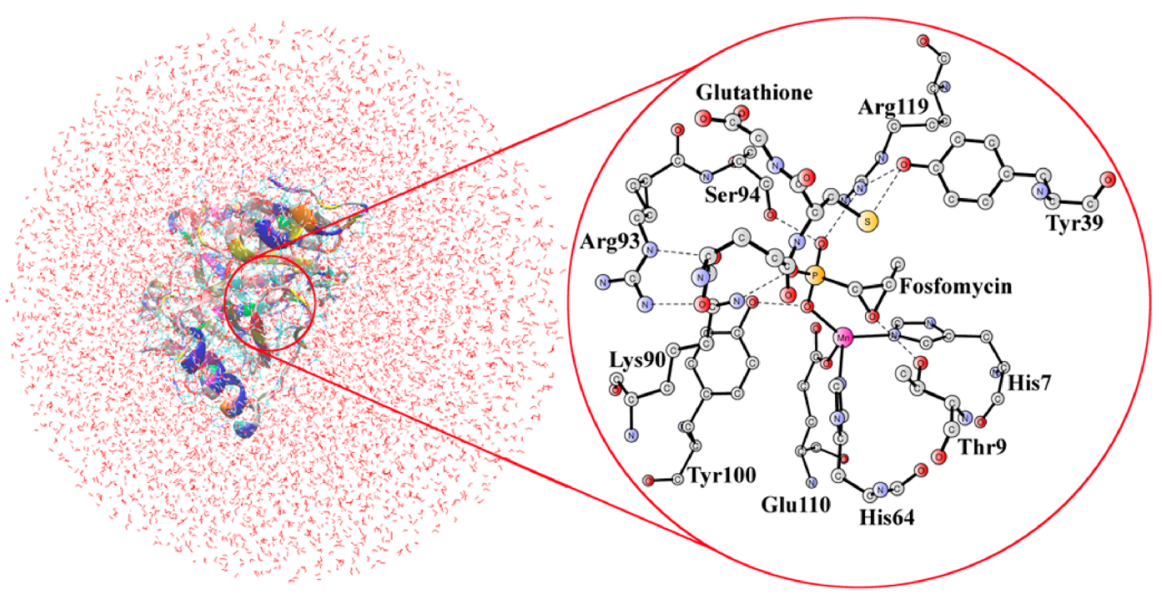

Figure 1. System used in QM/MM calculations. On the right side, an enlarged view is displayed for the important active-site residues and substrates. For clarity, hydrogen atoms are not shown. 


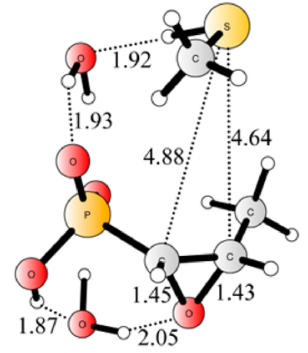

React

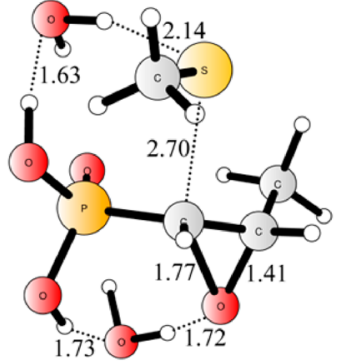

$\mathrm{TS}_{\mathrm{C} 1}$

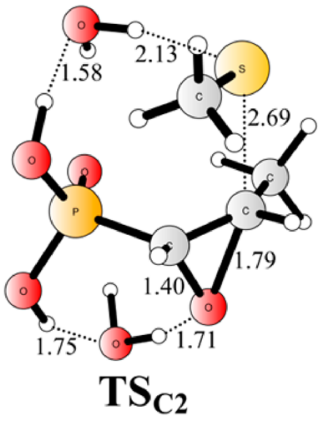

$\mathbf{T S}_{\mathrm{C} 2}$
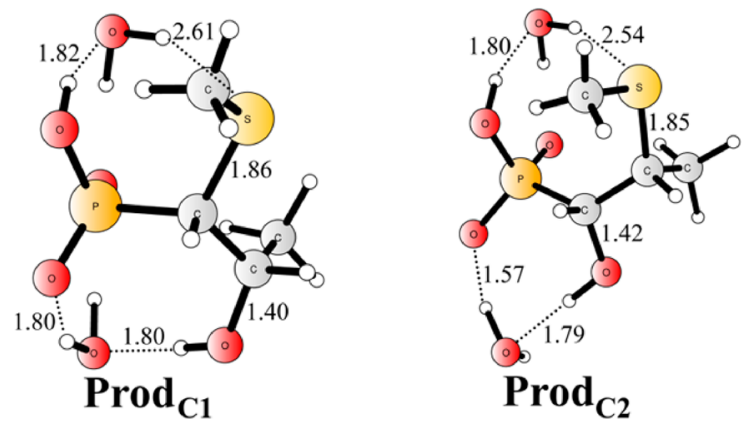

Figure 2. Optimized structures of stationary points for the uncatalyzed reaction. Distances in $\AA$.

free energies including zero-point vibrational corrections, thermal corrections at $298 \mathrm{~K}$, and solvation free energy corrections. For the M06, $\omega$ B97X, and B2PLYP free energies, these corrections were taken from the B3LYP calculations.

2.2. Setup of the Model System. The initial geometry was built from the $\mathrm{X}$-ray structure of FosA from $P$. aeruginosa complexed with fosfomycin (PDB code: 1LQP, resolution 1.19 $\AA) .{ }^{13}$ The dimeric form was used, and an active region for the setup was selected containing residues within $30 \AA$ of the $\mathrm{Mn}$ atom of chain $\mathrm{A}$. The protonation states of the titratable residues (His, Asp, and Glu) were determined on the basis of their $\mathrm{p} K_{\mathrm{a}}$ values obtained via the PROPKA ${ }^{51}$ program (see Supporting Information for details) and verified by visual inspection of the hydrogen-bonding environment of the residues assuming $\mathrm{pH}=8$ (the working $\mathrm{pH}$ of FosA). ${ }^{11}$ The anionic form was chosen for Tyr39 of chain A, which has been proposed to function as the catalytic base for GSH deprotonation. ${ }^{24}$ A GSH molecule was docked into the active site of chain A using Autodock Vina, ${ }^{52}$ in the conformation proposed for the binding mode of GSH on the basis of docking and mutational studies by Armstrong and co-workers. ${ }^{24}$ The total charge of the model system was zero.

The dimeric enzyme was solvated in a water droplet of $40 \AA$ radius centered at the $\mathrm{Mn}$ atom of chain A. Following energy minimization, the solvated system was subjected to a $1 \mathrm{~ns}$ molecular dynamics (MD) simulation at $300 \mathrm{~K}$ using the $\mathrm{CHARMM}^{53}$ force field as implemented in the CHARMM program. ${ }^{54}$ During the simulation, we fixed residues more than $30 \AA$ away from the $\mathrm{Mn}$ atom of chain $\mathrm{A}$, as well as the metal ions and the non-hydrogen atoms of the ligands His7, His64, Glu110 and the fosfomycin substrate. The equilibrated system (Figure 1) is composed of 30674 atoms, including 8817 TIP3 water molecules.

To investigate the alternative water attack on fosfomycin in FosA, the GSH substrate was removed, and the system was solvated using the same procedure as before and neutralized by adding one chloride ion. This was followed by 1 ns equilibration with exactly the same constraints applied as described above.

2.3. QM/MM Calculations of the Enzymatic Reaction. The QM/MM calculations for the enzymatic reaction were performed using Chemshell ${ }^{55,56}$ interfaced with Turbomole ${ }^{57}$ and DL-POLY. ${ }^{58}$ An electronic embedding scheme was applied to incorporate the polarization effect of the MM part on the QM region. Hydrogen link atoms and the charge shift model were employed to treat the QM/MM boundary. No electrostatic cutoff was adopted for the QM/MM interactions. The CHARMM force field was used for the MM region. The active region for $\mathrm{QM} / \mathrm{MM}$ geometry optimization included the QM atoms, all residues, and all water molecules in the $\mathrm{MM}$ region within $13 \AA$ of $\mathrm{C} 1$ of fosfomycin (see Supporting Information for details).

Two different QM regions (87 atoms for M1a and 170 atoms for M2a, total charge of 0 ) were selected to study the GSH attack in the QM/MM calculations. QM region M1a consisted of the $\mathrm{Mn}^{2+}$ ion along with the side chains of its ligands His7, His64, and Glu110. Furthermore, four important second-shell residues, Thr9, Tyr39, Lys90, and Arg119, were included, as well as all atoms of fosfomycin and the functional ethanethiol part of the GSH substrate. The larger QM region M2a was chosen to cover all important interactions around the two substrates. In addition to the atoms selected in Mla, it contained the full GSH substrate, the residues Arg93, Ser94, and Tyr100, which are hydrogen-bonding partners of the two substrates, and nine water molecules around the active site. For studying the water attack, all atoms in M1a were included except ethanethiol, which was replaced by a water molecule in QM region $\mathbf{M 1 b}$ (81 atoms, total charge of 0 ). For the larger QM region $\mathbf{M 2 b}$ (170 atoms, total charge of +1 ), all QM atoms except GSH from M2a were included and 12 water molecules in the active-site cavity were added.

For QM/MM geometry optimizations, the QM part was treated with the B3LYP functional using the def2-SVP basis set for all elements. More accurate energies were evaluated by single-point calculations with the larger def2-TZVPP basis set. 
Empirical dispersion corrections (DFT-D2) $)^{59}$ were also included. TS optimizations were performed with the partitioned rational function optimizer (P-RFO) using the Powell update for an explicit Hessian. ${ }^{60}$ Numerical frequency calculations were carried out for selected core atoms to characterize the nature of the optimized TS (only one imaginary frequency).

\section{RESULTS AND DISCUSSION}

3.1. Uncatalyzed Reaction. To assess the rate enhancement achieved by FosA, we first investigated the uncatalyzed reaction with the assistance of two water molecules involved in proton transfer. Methanethiol was used to mimic the GSH substrate for the sake of efficiency and also to avoid conformational problems. Thus the model system for the uncatalyzed reaction consisted of a monoanionic fosfomycin substrate, methanethiol, and two water molecules. Monoanionic fosfomycin was chosen because it may function as base to deprotonate the thiol and as acid to protonate the leaving group. The measured $\mathrm{p} K_{\mathrm{a} 2}$ of fosfomycin lies in the range of 6$7,{ }^{61,62}$ suggesting that a monoprotonated form can be easily formed under experimental conditions $(\mathrm{pH}=8) .{ }^{11}$ The model system has 26 atoms and a total charge of -1 . The optimized reactant complex, transition states, and product complexes for the attack on both $\mathrm{C} 1$ and $\mathrm{C} 2$ are displayed in Figure 2, and the calculated free energy barriers and reaction free energies at various levels are given in Table 1.

Table 1. Calculated Free Energy Barriers and Reaction Free Energies (in $\mathrm{kcal} / \mathrm{mol}$ ) for the Uncatalyzed Reaction at Various Levels

$\begin{array}{ccccc} & \text { B3LYP } & \text { M06 } & \omega \text { B97X } & \text { B2PLYP } \\ \text { React } & 0 & 0 & 0 & 0 \\ \mathrm{TS}_{\mathrm{C} 1} & 29.7 & 29.5 & 35.4 & 28.6 \\ \mathrm{TS}_{\mathrm{C} 2} & 29.9 & 29.9 & 35.1 & 29.4 \\ \text { Prod }_{\mathrm{C} 1} & -22.4 & -25.4 & -25.3 & -25.6 \\ \text { Prod }_{\mathrm{C} 2} & -22.8 & -23.3 & -24.7 & -25.3 \\ \mathrm{C} 1: C 2^{a} & 1.4: 1 & 1.9: 1 & 1: 1.6 & 3.7: 1\end{array}$

${ }^{a}$ Product ratio; the experimental value is $1: 1.5$.

The opening of the epoxide takes place in a single concerted step through an $\mathrm{S}_{\mathrm{N}} 2$ mechanism, without any intermediate, as confirmed by IRC calculations (Figure S1, see the Supporting Information). The calculated free energy barriers for the attack on $\mathrm{C} 1$ and $\mathrm{C} 2$ are 29.7 and $29.9 \mathrm{kcal} / \mathrm{mol}$, respectively, at the B3LYP level. The M06 and B2PLYP methods give very similar barriers, while the $\omega \mathrm{B} 97 \mathrm{X}$ functional yields somewhat higher barriers (see Table 1). The reaction is exothermic by more than $20 \mathrm{kcal} / \mathrm{mol}$ for the attack at each position, implying that it is irreversible and that regioselectivity can only arise from kinetic control. The product ratio of $\mathrm{C} 1$ adduct and $\mathrm{C} 2$ adduct has been measured to be $40 \%$ vs $60 \%$ in favor of $\mathrm{C} 2$ attack. $^{11}$ B3LYP, M06, and B2PLYP predict the attack on C1 to be slightly more facile, while $\omega \mathrm{B} 97 \mathrm{X}$ slightly favors the attack on C2 (with a product ratio of 1:1.6 which is fortuitously close to the experimental ratio of $1: 1.5)$. However, given the small differences between the computed barriers $(0.2-0.8 \mathrm{kcal} / \mathrm{mol}$, see Table 1) and considering the error bars of the DFT methods used, the main qualitative prediction is that the uncatalyzed reaction is not regioselective, which is compatible with the experimental findings.
During the reaction, the phosphonate plays a dual role as a general base to deprotonate methanethiol and as a general acid to protonate the leaving oxyanion. The geometries of the two transition states $\left(\mathrm{TS}_{\mathrm{C} 1}\right.$ and $\mathrm{TS}_{\mathrm{C} 2}$, Figure 2) suggest an asynchronous proton transfer featuring a well-developed thiolate prior to the relatively late protonation of the oxirane oxygen. An early deprotonation of methanethiol is consistent with the fact that it has relatively low $\mathrm{pK}_{\mathrm{a}}$ value (10.4) compared with water or alcohols $(\sim 15)$.

The bimolecular rate constant for the addition of GSH to fosfomycin has been measured to be $1.4 \times 10^{-8} \mathrm{M}^{-1} \mathrm{~s}^{-1}$ at 25 ${ }^{\circ} \mathrm{C}(\mathrm{pH}=8),{ }^{11}$ which can be converted to a barrier of around $28 \mathrm{kcal} / \mathrm{mol}$ using classical transition state theory. The barriers calculated with the B3LYP, M06, and B2PLYP functionals agree well with the experimental result (within $2 \mathrm{kcal} / \mathrm{mol}$ ), while $\omega \mathrm{B} 97 \mathrm{X}$ overestimates this value (by $7 \mathrm{kcal} / \mathrm{mol}$ ).

3.2. Enzymatic GSH Addition. In this section, we present our QM/MM results for GSH addition using two different QM regions (87 atoms for M1a and 170 atoms for M2a, total charge of 0$). \mathrm{Mn}^{2+}$ has a $3 \mathrm{~d}^{5}$ configuration, and all three possible spin states were considered, namely doublet, quartet, and sextet.

3.2.1. QM Region M1a. Five snapshots (labeled as Sn1$\mathrm{Sn} 5)$ were selected from MD simulations, corresponding to structures taken after $600,700,800,900$, and 1000 ps, respectively. The optimized reactant complex ( ${ }^{6}$ React) for $\mathrm{Sn} 1$ is shown in Figure 3, and the ordering and relative energies of

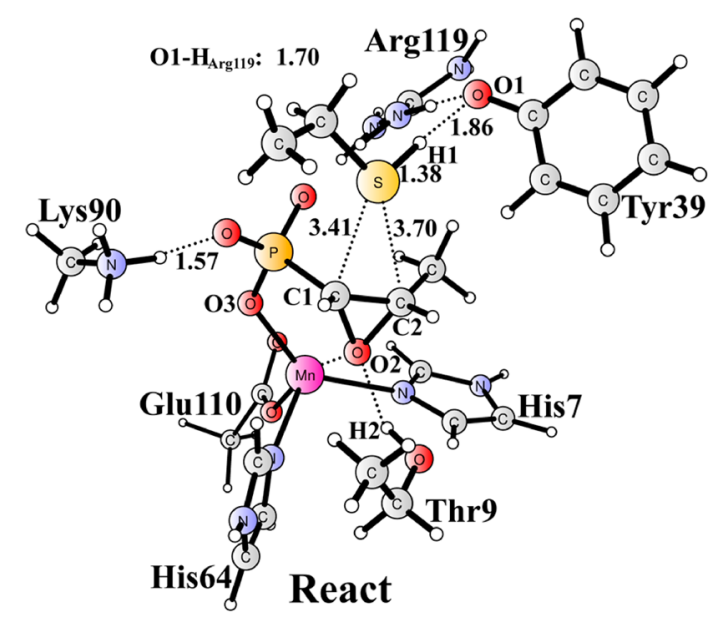

Figure 3. $\mathrm{QM}(\mathrm{B} 3 \mathrm{LYP} / \mathrm{def} 2-\mathrm{SVP}) / \mathrm{MM}$ optimized enzyme-reactant complex for GSH attack ( ${ }^{6}$ React, QM region M1a) with definition of atom labels. Important distances are given in $\AA$.

the lowest-lying spin states (sextet, quartet, and doublet) for all five snapshots are displayed in Figure 4. In all cases, the sextet spin state is the ground state, which is in agreement with EPR studies. $^{21,22}$ A high-spin sextet has also been found to be the ground state for other $\mathrm{Mn}^{2+}$ complexes on the basis of quantum chemical calculations. ${ }^{63-66}$ The quartet and doublet spin states lie more than $30 \mathrm{kcal} / \mathrm{mol}$ higher, and they are thus energetically not accessible under mild conditions. Since all five snapshots predict the same spin state ordering and very similar energy gaps, we decided to consider only the sextet spin state and to use $\operatorname{Sn} 1$ for further study, which is believed to represent the real system quite well.

The overall geometric parameters of ${ }^{6}$ React obtained from $\mathrm{QM} / \mathrm{MM}$ geometry optimization reproduce the $\mathrm{X}$-ray structure reasonably well. The $\mathrm{Mn}^{2+}$ ion is pentacoordinated with a trigonal-bipyramidal arrangement of the ligands. The two axial 


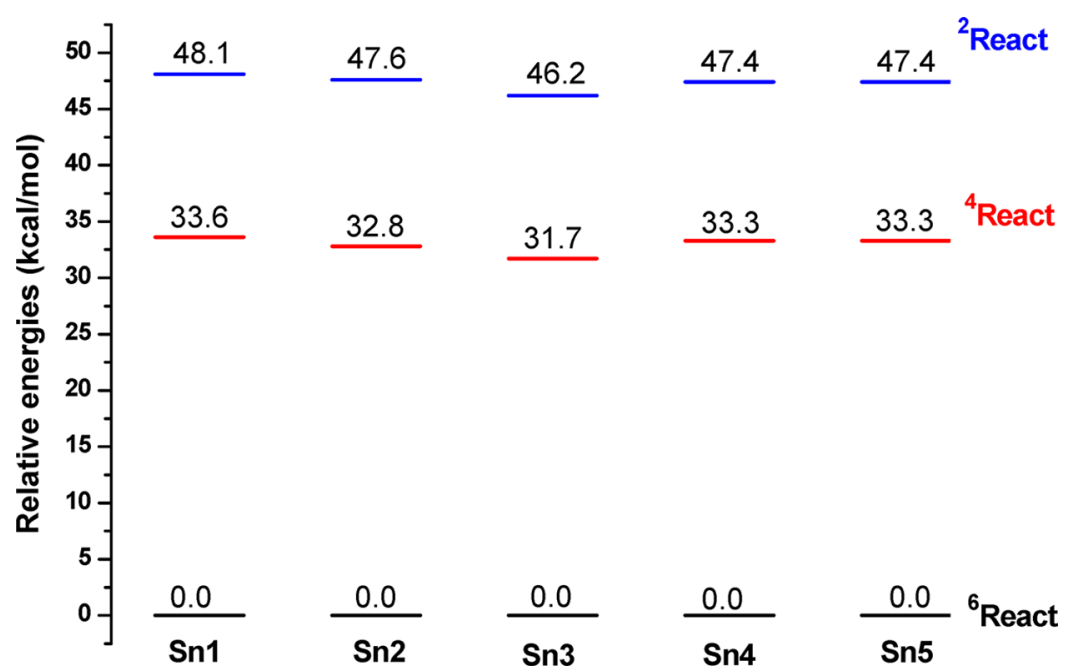

Figure 4. Relative energies in $\mathrm{kcal} / \mathrm{mol}$ of the lowest-lying sextet, quartet, and doublet spin states of the enzyme-reactant complex using five different snapshots and QM region M1a.

Table 2. Important Interatomic Distances in Å for Various Stationary Points during GSH Attack Using QM Region M1a (Sn1, B3LYP/MM) ${ }^{a}$

\begin{tabular}{|c|c|c|c|c|c|c|}
\hline & $\mathrm{Mn}-\mathrm{O} 2$ & $\mathrm{Mn}-\mathrm{O} 3$ & $\mathrm{Mn}-\mathrm{O}_{\mathrm{Glu} 110}$ & $\mathrm{Mn}-\mathrm{N}_{\mathrm{His} 7}$ & $\mathrm{Mn}-\mathrm{N}_{\mathrm{His} 64}$ & $\mathrm{O} 2-\mathrm{H} 2$ \\
\hline $\mathrm{X}$-ray & 2.34 & 2.03 & 2.06 & 2.11 & 2.14 & - \\
\hline${ }^{6}$ React & 2.32 & 2.08 & 2.05 & 2.30 & 2.22 & 1.89 \\
\hline${ }^{4}$ React & 2.11 & 2.07 & 1.98 & 2.14 & 2.25 & 1.94 \\
\hline${ }^{2}$ React & 2.14 & 2.05 & 1.98 & 2.15 & 2.15 & 1.92 \\
\hline${ }^{6} \mathrm{TS} 1$ & 2.34 & 2.05 & 2.05 & 2.28 & 2.21 & 1.90 \\
\hline${ }^{6}$ Int1 & 2.35 & 2.05 & 2.05 & 2.28 & 2.21 & 1.90 \\
\hline${ }^{6} \mathrm{TS} 2_{\mathrm{C} 1}$ & 2.18 & 2.12 & 2.08 & 2.35 & 2.22 & 1.80 \\
\hline${ }^{6} \mathrm{TS} 2_{\mathrm{C} 2}$ & 2.20 & 2.12 & 2.08 & 2.34 & 2.22 & 1.81 \\
\hline${ }^{6} \operatorname{Prod}_{\mathrm{C} 1}$ & 2.06 & 2.18 & 2.12 & 2.38 & 2.23 & 1.60 \\
\hline${ }^{6} \operatorname{Prod}_{\mathrm{C} 2}$ & 2.08 & 2.15 & 2.12 & 2.37 & 2.23 & 1.70 \\
\hline
\end{tabular}

${ }^{a}$ For definition of atomic labels see Figure 3.

$\mathrm{Mn}-\mathrm{O} 2$ and $\mathrm{Mo}-\mathrm{O}_{\mathrm{Glu} 110}$ bonds have distances of 2.05 and $2.32 \AA$ (Table 2), respectively, which are in excellent agreement with the crystallographic values (2.06 and $2.34 \AA$, respectively). In addition, the hydrogen bond between Thr9 and the fosfomycin oxirane oxygen is well reproduced. There are larger deviations, however, between the calculated distances of the two equatorial $\mathrm{Mn}-\mathrm{N}_{\mathrm{His} 7}$ and $\mathrm{Mn}-\mathrm{N}_{\mathrm{His} 64}$ bonds (2.30 and 2.22 $\AA$, respectively) and those observed in the more compact crystal structure (2.11 and $2.14 \AA$, respectively). The strategically located Tyr39 residue is hydrogen-bonded to $\operatorname{Arg} 119$ and the thiol group of GSH, with hydrogen bond distances of 1.70 and $1.86 \AA$, respectively. These interactions help stabilize the tyrosinate and orient the thiol group of GSH such that it is ready for deprotonation, which is required for the nucleophilic attack. The GSH orientation in the active site appears to favor attack on $\mathrm{C} 1$, as the $\mathrm{S}-\mathrm{C} 1$ distance is approximately $0.3 \AA$ shorter than the $\mathrm{S}-\mathrm{C} 2$ distance, suggesting a preference for regioselective attack on $\mathrm{C} 1$. The analysis of MD trajectories (Supporting Information, Figure S2) confirms that the GSH sulfur atom tends to be closer to C1 (average distance of $3.45 \AA$ ) than to C2 (average distance of $3.84 \AA$ ).

Starting from ${ }^{6}$ React, a linear transit (see Supporting Information) was performed for the deprotonation of GSH with Tyr39 as proton acceptor, and the highest point was used as a starting structure for transition state optimization. The transition state $\left({ }^{6} \mathrm{TS} 1\right)$ and the leading intermediate $\left({ }^{6}\right.$ Int1) are displayed in Figure 5. The barrier is calculated to be $6.0 \mathrm{kcal} /$ mol at the QM(B3LYP-D2/def2-TZVPP)/MM level (Figure 6), and ${ }^{6}$ Int1 lies at $+6.8 \mathrm{kcal} / \mathrm{mol}$, which is $0.8 \mathrm{kcal} / \mathrm{mol}$ above ${ }^{6} \mathrm{TS} 1$, suggesting a barrierless proton transfer back to thiolate. This is of course an artifact of the technical procedure employed, as the geometries were optimized with the smaller def2-SVP basis set while the final single-point energies were calculated with the larger def2-TZVPP basis set. The critical $\mathrm{O} 1-\mathrm{H} 1$ and $\mathrm{S}-\mathrm{H} 1$ distances are 1.19 and $1.69 \AA$ in ${ }^{6} \mathrm{TS} 1$, and they become 1.09 and $1.85 \AA$ in ${ }^{6}$ Int1, respectively.

In the following step, the nucleophilic attack can be directed to either the $\mathrm{C} 1$ or $\mathrm{C} 2$ position. The optimized transition states $\left({ }^{6} \mathrm{TS} 2_{\mathrm{C} 1}\right.$ and $\left.{ }^{6} \mathrm{TS} 2_{\mathrm{C} 2}\right)$ and the resulting products $\left({ }^{6} \operatorname{Prod}_{\mathrm{C} 1}\right.$ and $\left.{ }^{6} \operatorname{Prod}_{\mathrm{C} 2}\right)$ are shown in Figure 5. It should be noted that the epoxide ring-opening by an acid catalyst, like $\mathrm{Mn}^{2+}$ in the present case, may involve carbocation formation and an $S_{N} 1$ reaction mechanism. We find, however, that $\mathrm{C}-\mathrm{O}$ bond cleavage proceeds concomitant with $\mathrm{C}-\mathrm{S}$ bond formation through a one-step $S_{\mathrm{N}}$ 2-like reaction mechanism. The barrier for the nucleophilic attack at C1 is calculated to be $11.2 \mathrm{kcal} /$ mol relative to ${ }^{6}$ React, and the overall reaction is exergonic by as much as $19.0 \mathrm{kcal} / \mathrm{mol}$. In ${ }^{6} \mathrm{TS} 2_{\mathrm{C} 1}$, the distance between the $\mathrm{C} 1$ and $\mathrm{S}$ atoms is $2.71 \AA$, and the oxirane ring is partially opened with a $\mathrm{C} 1-\mathrm{O} 2$ distance of $1.78 \AA$. Due to the development of negative charge on $\mathrm{O} 2$, the distance between $\mathrm{O} 2$ and $\mathrm{Mn}^{2+}$ is shortened from $2.35 \AA$ in ${ }^{6}$ Int1 to $2.18 \AA$ in 

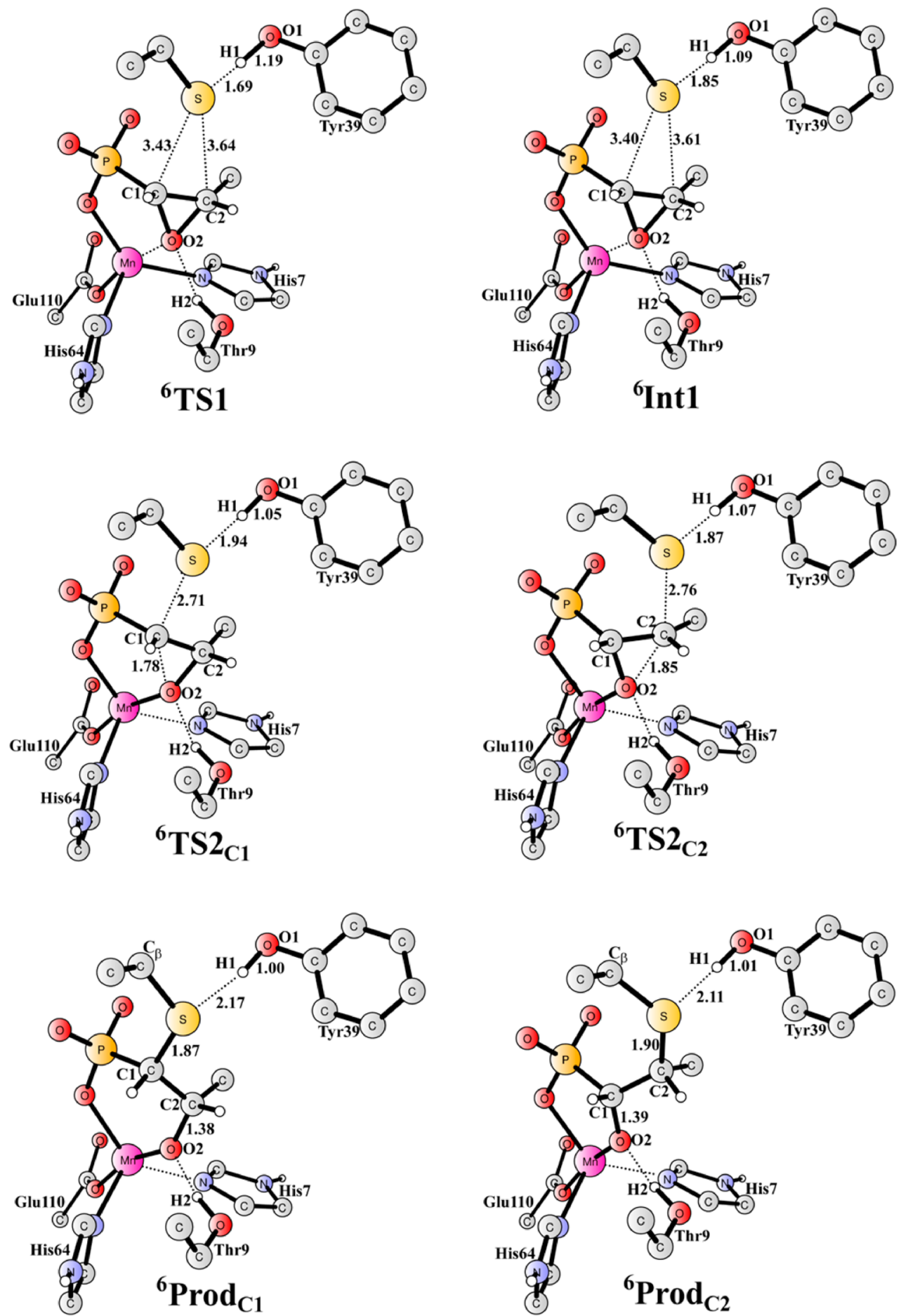

Figure 5. Optimized structures of transition states, intermediate, and products for GSH attack with QM region M1a (B3LYP/MM). All bond lengths are given in $\AA$. For clarity, Lys90, Arg119, and unimportant hydrogen atoms are not shown. For the full QM region, see Figure 3.

${ }^{6} \mathrm{TS2}_{\mathrm{C} 1}$ and $2.06 \AA$ in ${ }^{6} \operatorname{Prod}_{\mathrm{C} 1}$. The $\mathrm{Mn}^{2+}$ ion thus plays an important role in stabilizing the emerging oxyanion, thereby facilitating the ring-opening. In addition, the hydrogen bond from Thr9 to $\mathrm{O} 2$ becomes stronger, as indicated by the decrease of the hydrogen bond distance from $1.90 \AA$ in ${ }^{6}$ Int1 to $1.80 \AA$ in ${ }^{6} \mathrm{TS} 2_{\mathrm{C} 1}$ and further to $1.60 \AA$ in ${ }^{6} \operatorname{Prod}_{\mathrm{C} 1}$. For the attack at $\mathrm{C} 2$, the barrier is calculated to be $18.1 \mathrm{kcal} / \mathrm{mol}$, which is $6.9 \mathrm{kcal} / \mathrm{mol}$ higher than the barrier calculated for attack at C1. In addition, ${ }^{6}$ Prod $_{\mathrm{C} 2}$ lies only $5.0 \mathrm{kcal} / \mathrm{mol}$ below ${ }^{6}$ React and more than $10 \mathrm{kcal} / \mathrm{mol}$ above ${ }^{6} \operatorname{Prod}_{\mathrm{Cl}}$. The computed energies clearly indicate that attack is preferred at $\mathrm{C} 1$, which is in agreement with the experimental results. ${ }^{9-13}$ In ${ }^{6} \mathrm{TS}_{\mathrm{C} 2}$, the $\mathrm{C} 2-\mathrm{S}$ and $\mathrm{C} 2-\mathrm{O} 2$ distances are 2.76 and $1.85 \AA$, respectively, both slightly longer than in ${ }^{6} \mathbf{T S} 2_{\mathrm{C} 1}$, indicating a slightly more dissociative character of the transition state for attack at $\mathrm{C} 2$.

3.2.2. QM Region M2a. The larger QM region M2a was defined with the objective to better describe the electronic environment of the two substrates. Arg93, Ser94, and Tyr100, being hydrogen bonding partners of fosfomycin and GSH, were added to QM region M1a, as well as nine water molecules near 
M1a

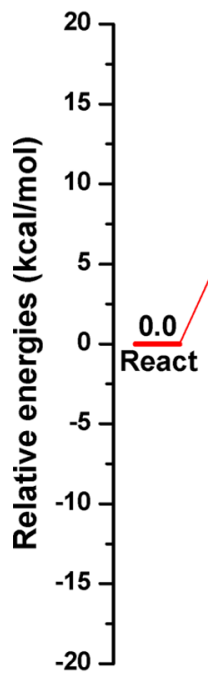

M2a

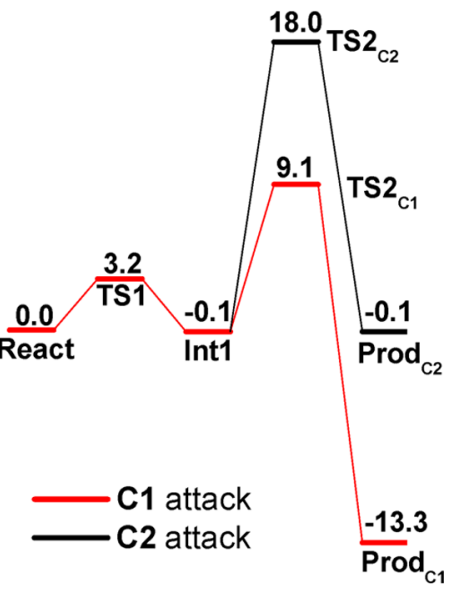

$\operatorname{Prod}_{\mathrm{C} 1}$

$-19.0$

$\overline{\text { Prod }}_{\mathrm{C} 1}$

Figure 6. Calculated QM/MM potential energy profiles for GSH attack in the sextet state using QM region M1a (left) and M2a (right).

the substrates. In addition, the whole GSH molecule was included in the model. QM region M2a is thus composed of $170 \mathrm{QM}$ atoms (Figure 7), and the total charge is 0 (same as in

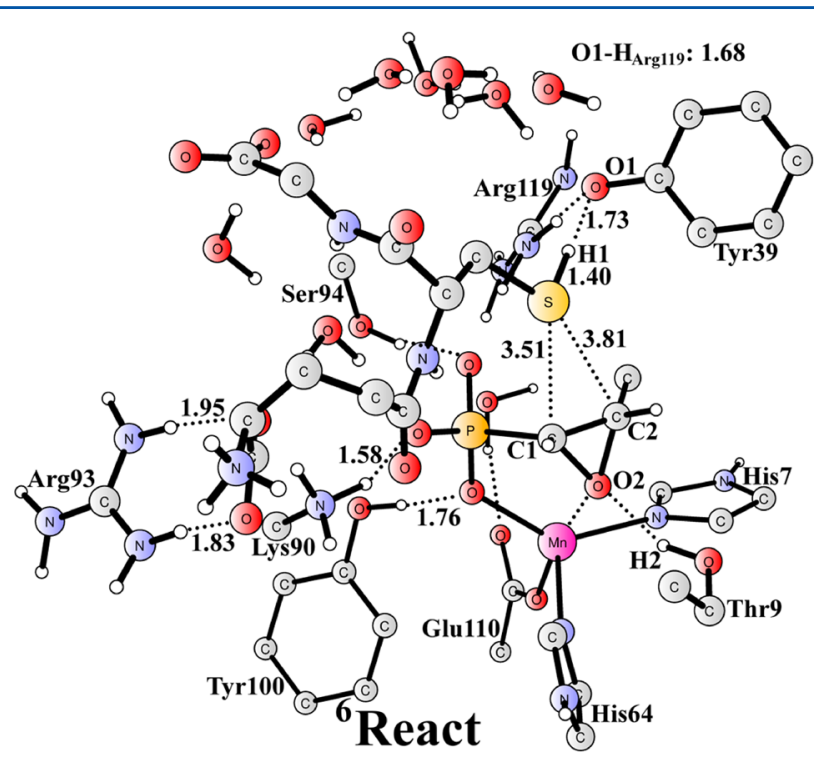

Figure 7. Optimized structure of the reactant complex ( ${ }^{6}$ React) for $\mathrm{QM}$ region M2a (B3LYP/MM). For clarity, unimportant hydrogen atoms are not shown. Distances are given in $\AA$.

M1a). All stationary points were reoptimized. The resulting structures are shown in the Supporting Information (Figures
S6-S9), and the relative energies are given in Figure 6. For the reactant complex, the sextet is the ground state, and the quartet and doublet states are 32.7 and $47.3 \mathrm{kcal} / \mathrm{mol}$ higher, respectively, in close analogy to the results for M1a (Figure 4). The extension of the QM region leads to considerable stabilization of ${ }^{6}$ Int 1, which is now almost isoenergetic to the reactant complex. Consequently, the barrier for the initial proton transfer drops to only $3.2 \mathrm{kcal} / \mathrm{mol}$. The transition state for the following nucleophilic attack at $\mathrm{C} 1$ lies $9.1 \mathrm{kcal} / \mathrm{mol}$ above ${ }^{6}$ React (slightly lower than in the case of M1a, $11.2 \mathrm{kcal} /$ $\mathrm{mol}$ ). The attack at $\mathrm{C} 2$ is even more disfavored than before, since the overall barrier is $8.9 \mathrm{kcal} / \mathrm{mol}$ higher than that for attack at $\mathrm{C} 1$ (compared with a difference of $6.9 \mathrm{kcal} / \mathrm{mol}$ for M1a).

As can be inferred from Figure 6, alkylation takes place exclusively at position $\mathrm{C} 1$ and the second step is rate-limiting, with a barrier of $9.2 \mathrm{kcal} / \mathrm{mol}$ relative to ${ }^{6}$ Int1 (QM region M2a). Experimental rate constants have been reported in the range of $65-1070 \mathrm{~s}^{-1} \cdot 10,11,23,24$ This can be converted to barriers in the range of $13-15 \mathrm{kcal} / \mathrm{mol}$ using classical transition state theory. Our calculated barrier with QM region M2a is thus somewhat underestimated, but the large difference in the barriers for $\mathrm{C} 1$ and $\mathrm{C} 2$ attack is in line with the experimental observation that the GSH attack occurs solely at the $\mathrm{C} 1$ position. By comparing with the uncatalyzed reaction, we find a decrease in the computed barrier of about $20 \mathrm{kcal} /$ mol, corresponding to a rate enhancement of the order of $10^{14}$. The enzyme catalyzes the reaction by providing a general base (Tyr39) and a Lewis acid $\left(\mathrm{Mn}^{2+}\right.$ ion). The use of a base for nucleophile deprotonation and of an acid for leaving-group

Table 3. Distortion Energies and Interaction Energies (in $\mathrm{kcal} / \mathrm{mol}$ ) of the Transition States for GSH and Water Attack on C1 and $\mathrm{C} 2$

\begin{tabular}{ccccccc}
\hline attack molecule & & $\Delta E_{\text {dist }}^{\ddagger}(\mathrm{Nuc})^{a}$ & $\Delta E_{\text {dist }}^{\ddagger}($ Elc $)$ & $\Delta E_{\text {int }}^{\ddagger}$ & $\Delta E^{\ddagger}$ & selectivity \\
GSH & ${ }^{6} \mathbf{T S 2}_{\mathrm{C} 1}$ & 2.4 & 17.6 & -14.4 & 5.6 & $4.8\left(8.9^{b}\right)$ \\
& ${ }^{6} \mathrm{TS}_{\mathrm{C} 2}$ & 3.7 & 23.4 & -16.7 & 10.4 & \\
$\mathrm{H}_{2} \mathrm{O}$ & ${ }^{6} \mathrm{TS}_{\mathrm{C} 1}$ & 1.9 & 33.5 & -12.9 & 22.5 & $5.3\left(4.1^{b}\right)$ \\
& ${ }^{6} \mathrm{TS}_{\mathrm{C} 2}$ & 1.5 & 26.0 & -9.7 & 17.2 &
\end{tabular}

${ }^{a} \mathrm{Nuc}$ is GSH-S ${ }^{-}$thiolate for GSH attack and $\mathrm{H}_{2} \mathrm{O}$ for water attack ${ }^{b}$ Barrier difference at the QM(B3LYP)/MM level 
protonation or stabilization is a common theme in enzyme catalysis and has also been observed in other epoxidases. ${ }^{35-41}$ In addition, two positively charged residues (Lys90 and Arg119) help shield the negative charge of the phosphonate moiety, thereby reducing its electrostatic repulsion with the nucleophile during the attack. The presence of the anionic phosphonate group has been suggested to account for the resistance of fosfomycin to nucleophilic attack. ${ }^{10}$

To unveil the source of regioselectivity, we conducted a distortion/interaction analysis, which has been shown to be a powerful tool for explaining reactivity trends. ${ }^{67-71}$ In this analysis, the QM region is decomposed into two parts, the nucleophile (labeled as Nuc, GSH anion) and the electrophile (labeled as Elc, fosfomycin with all other residues except the GSH anion). Gas-phase single-point calculations at the B3LYP/ def2-TZVPP level were performed for each part in ${ }^{6}$ Int1, ${ }^{6} \mathrm{TS}_{\mathrm{C} 1}$, and ${ }^{6} \mathrm{TS}_{\mathrm{C} 2}$. The total activation energy for the $\mathrm{QM}$ region $\left(\Delta E^{\dagger}\right)$ is decomposed into the sum of the distortion energies of each moiety $\left(\Delta E_{\text {dist }}^{\ddagger}\right)$ and the interaction energy $\left(\Delta E_{\text {int }}^{\ddagger}\right)$ between the two distorted moieties. Table 3 lists these energies for the transition states. In the case of the GSH attack, the distortion energy at $\mathrm{C} 2(27.1 \mathrm{kcal} / \mathrm{mol})$ is significantly higher than that at $\mathrm{C} 1(20.0 \mathrm{kcal} / \mathrm{mol})$, while the interaction energy is of similar magnitude. The larger distortion can be also recognized from the geometric changes. When passing from ${ }^{6}$ Int1 to ${ }^{6} \mathrm{TS}_{\mathrm{C} 1}$, the epoxide angle $(\mathrm{C} 1 \mathrm{C} 2 \mathrm{O} 2)$ increases by $18.8^{\circ}$, from $60.7^{\circ}$ to $79.5^{\circ}$, while the corresponding angle for $\mathrm{C} 2$ attack rises by $24.8^{\circ}$, from $59.2^{\circ}$ to $84.0^{\circ}$. The increase of this angle has been shown to correlate with the regioselectivity and reactivity in QM/MM studies of inhibition of cysteine protease by epoxide. $^{72,73}$ The regioselectivity for GSH attack is thus mainly distortion-controlled. The preference for $\mathrm{C} 1$ over C2 attack is further enhanced, from 4.8 to $8.9 \mathrm{kcal} / \mathrm{mol}$, by including the $\mathrm{MM}$ environment, as can be seen from the differences in the barriers computed at the $\mathrm{QM}$ and $\mathrm{QM} / \mathrm{MM}$ levels (Table 3). The enzyme thus arranges its active-site residues to favor the distorted fosfomycin moiety in the transition state for attack at $\mathrm{C} 1$.

3.3. Enzymatic Water Addition. As mentioned in the Introduction, the crystal structure of FosA in complex with fosfomycin has a water-accessible open pocket. ${ }^{13}$ However, water addition is not catalyzed by FosA, but by another enzyme (FosX). ${ }^{15-17}$ Theoretical calculations gave very similar barriers for alcohol and thiol attack on amide, ${ }^{74}$ and for thiolysis and alcoholysis of phosphate monoester, ${ }^{75}$ so that one might expect similar reactivity for GSH and water attack on fosfomycin. Here we consider the pathway for water attack in order to understand the chemoselectivity of the FosA enzyme. We report QM/MM results obtained with two QM regions (M1b and $\mathbf{M} 2 \mathbf{b}$ ) consisting of 87 and 170 atoms, respectively, with a total charge of 0 and +1 , respectively.

3.3.1. QM Region M1b. All three spin states, doublet, quartet, and sextet, were calculated for the reactant complex. The sextet is the ground state, and its structure ( ${ }^{6}$ React) is shown in Figure 8. The quartet and doublet lie much higher than the sextet, by 33.8 and $48.9 \mathrm{kcal} / \mathrm{mol}$, respectively. This energy ordering is very similar to the one found in the GSH case, indicating a rather small influence of GSH binding on the relative energies of the different spin states, which is plausible since GSH does not coordinate directly to the metal and the metal keeps its coordination mode before/after GSH binding. In ${ }^{6}$ React, a water molecule forms a hydrogen bond to the Tyr39 phenolate oxygen, with a distance of $1.76 \AA$. The

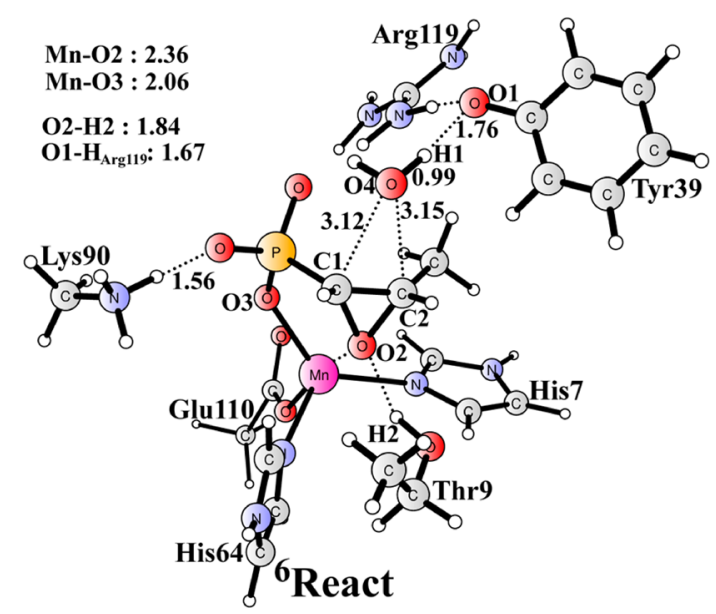

Figure 8. QM(B3LYP/def2-SVP)/MM optimized enzyme-reactant complex for water attack ( ${ }^{6}$ React, $Q M$ region $\left.\mathrm{M} 1 \mathrm{~b}\right)$ with definition of atom labels. Important interatomic distances are given in $\AA$.

distances between the water oxygen and the two carbon atoms (C1 and C2) are almost equal (3.12 and $3.15 \AA$, respectively). This is different from the GSH case, where ${ }^{6}$ React is more asymmetric (with the $\mathrm{S}-\mathrm{C} 1$ distance about $0.3 \AA$ shorter than $\mathrm{S}-\mathrm{C} 2$ ). The trace of geometric changes in the MD simulation (Figure S10) confirms that this water molecule remains hydrogen-bonded to Tyr39 (except for a very short time), and the water oxygen tends to be slightly closer to $\mathrm{C} 1$ than to $\mathrm{C} 2$, by $0.24 \AA$ on average (less so than in the case of GSH with a preference of $0.39 \AA$ ).

As discussed above, GSH addition proceeds via a stepwise mechanism in FosA, with the nucleophilic attack taking place after thiol deprotonation. Since water has a much higher $\mathrm{p} K_{\mathrm{a}}$ value than methanethiol (15.7 vs 10.4), the formation of a hydroxide intermediate seems to be rather unlikely. We could indeed only locate concerted transition states for the water attack, with proton transfer, nucleophilic attack, and ringopening occurring in a single step. The optimized transition states $\left({ }^{6} \mathrm{TS}_{\mathrm{C} 1}\right.$ and $\left.{ }^{6} \mathrm{TS}_{\mathrm{C} 2}\right)$ and the resulting product complexes $\left({ }^{6} \operatorname{Prod}_{\mathrm{C} 1}\right.$ and $\left.{ }^{6} \operatorname{Prod}_{\mathrm{C} 2}\right)$ are displayed in Figure 9. The barriers for water attack on $\mathrm{C} 1$ and $\mathrm{C} 2$ are calculated to be 20.3 and $17.1 \mathrm{kcal} / \mathrm{mol}$, respectively (Figure 10), with a preference for $\mathrm{C} 2$ by $3.2 \mathrm{kcal} / \mathrm{mol}$. Correspondingly, ${ }^{6} \operatorname{Prod}_{\mathrm{C} 2}$ is $3.6 \mathrm{kcal} / \mathrm{mol}$ lower than ${ }^{6} \operatorname{Prod}_{\mathrm{C} 1}$. At ${ }^{6} \mathrm{TS}_{\mathrm{C} 1}$, the nascent $\mathrm{C} 1-\mathrm{O} 4$ bond and the scissile $\mathrm{C} 1-\mathrm{O} 2$ bond are of equal length $(1.99 \AA)$, while the attack on $\mathrm{C} 2\left({ }^{6} \mathrm{TS}_{\mathrm{C} 2}\right)$ features a slightly earlier transition state, with $\mathrm{C} 2-\mathrm{O} 4$ and $\mathrm{C} 2-\mathrm{O} 2$ distances of 2.09 and $1.98 \AA$, respectively.

3.3.2. QM Region $M 2 b$. In analogy to our study of GSH attack, a larger QM region $\mathbf{M} 2 \mathbf{b}$ was also used to check the effect of different QM regions on the results for water attack. QM region $\mathbf{M} 2 \mathbf{b}$ differs from M2a in that 12 water molecules replace GSH. Therefore, the total number of atoms is the same (170), but the total charge is +1 rather than 0 (as GSH has a charge of -1). The potential energy profile is displayed in Figure 10, and all optimized structures are shown in the Supporting Information (Figures S11-S13). The calculated barriers and reaction energies are very close to those using QM region $\mathbf{M 1 b}$, with a maximum deviation of $1.3 \mathrm{kcal} / \mathrm{mol}$. The attack on $\mathrm{C} 2$ is now preferred by $4.1 \mathrm{kcal} / \mathrm{mol}$.

As can be seen from Figures 6 and 10, the lowest barrier for GSH attack is $9.2 \mathrm{kcal} / \mathrm{mol}\left({ }^{6} \mathrm{TS}_{\mathrm{C} 1}\right.$ relative to ${ }^{6} \mathrm{Int} 1, \mathrm{QM}$ region M2a) while the lowest barrier for water attack is 17.5 

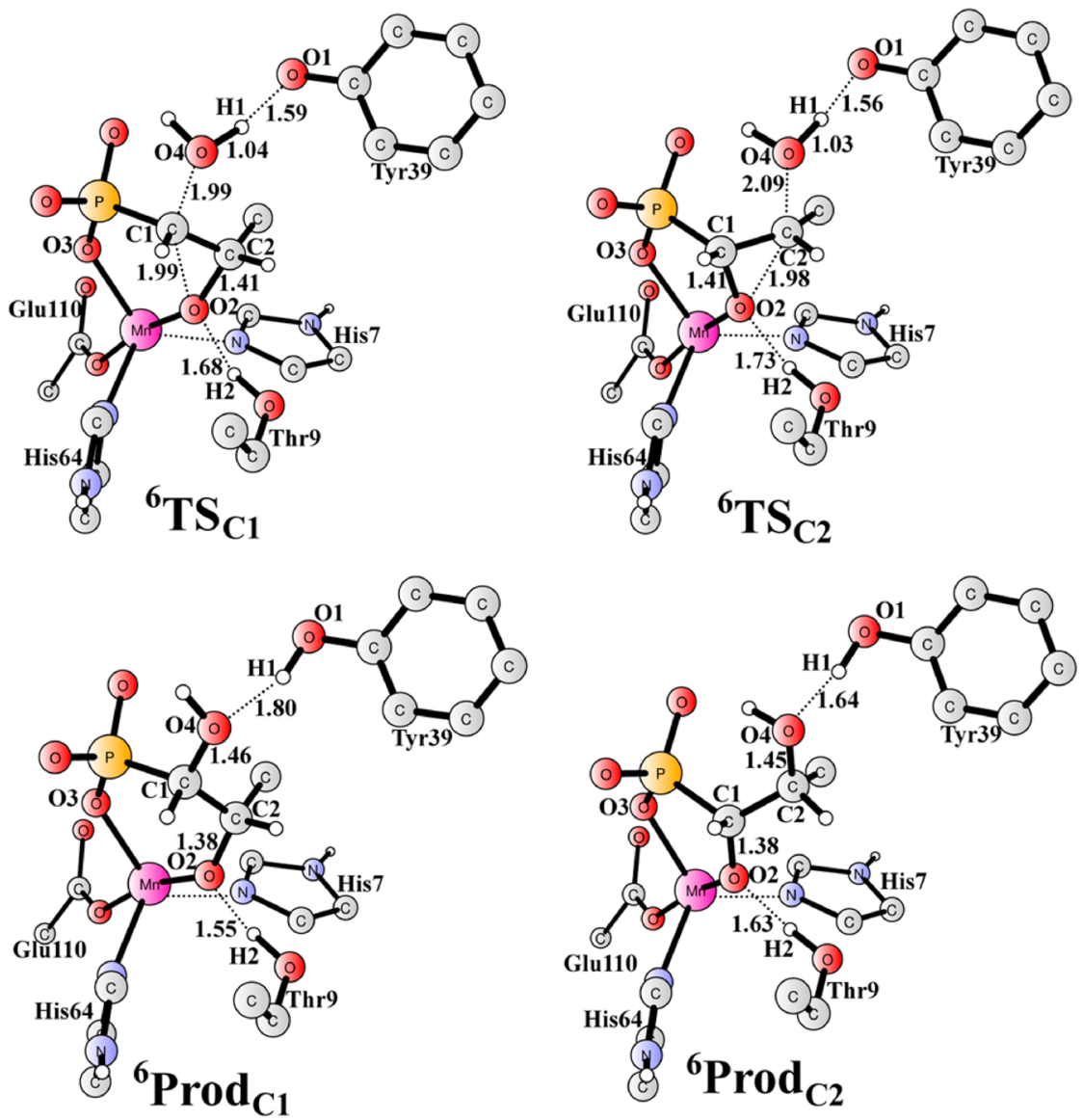

Figure 9. Optimized structures of transition states and products for water attack with QM region M1b (B3LYP/MM). All bond lengths are given in A. For clarity, Lys90, Arg119, and unimportant hydrogen atoms are not shown. For full QM region, see Figure 8.

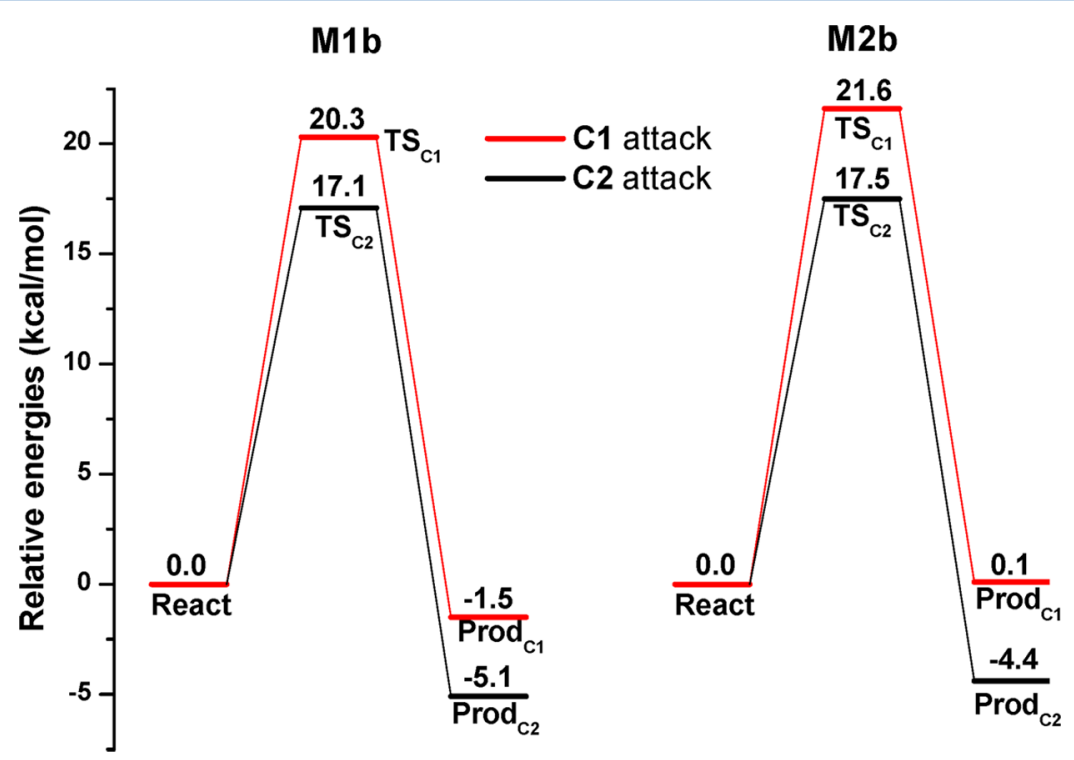

Figure 10. Calculated QM/MM potential energy profiles for water attack using QM region $\mathbf{M 1 b}$ (left) and M2b (right).

$\mathrm{kcal} / \mathrm{mol}\left({ }^{6} \mathrm{TS}_{\mathrm{C} 2}\right.$ relative to ${ }^{6}$ React, $\mathrm{QM}$ region $\left.\mathbf{M} 2 \mathrm{~b}\right)$. The distortion/interaction analysis (Table 3 ) indicates that the distortion energy is larger and the interaction energy is smaller for water attack than for GSH attack; thus, both contribute to the higher barrier. The regioselectivity is again governed by the distortion energy, which is significantly higher for water attack at $\mathrm{C} 1$ compared with $\mathrm{C} 2(35.4 \mathrm{vs} 27.5 \mathrm{kcal} / \mathrm{mol})$.
The calculated barrier for water attack seems to be underestimated, as a barrier of $17.5 \mathrm{kcal} / \mathrm{mol}$ can be converted to rate constant of about $1 \mathrm{~s}^{-1}$, which would indicate that water attack could take place when only fosfomycin is bound into the active site (not observed experimentally). We note in this context that the present calculations do not include entropic effects, which may be expected to raise the barrier for water 
attack (by several kcal/mol) because of the incorporation of an "initially free" water molecule in the well-ordered transition state. Moreover, the B3LYP functional will probably underestimate the barrier for water attack, in analogy to the GSH case where the B3LYP/MM barrier is too low by $4-6 \mathrm{kcal} / \mathrm{mol}$ compared with experimental kinetic data. Gas-phase singlepoint test calculations using the M06 functional indeed give a barrier for water attack at C2 that is $3.1 \mathrm{kcal} / \mathrm{mol}$ higher than the B3LYP value.

\section{CONCLUSION}

We report the first theoretical examination of the catalytic mechanism of fosfomycin resistance protein FosA, with particular focus on the regioselectivity and chemoselectivity. Reaction pathways have been explored for the uncatalyzed reaction and for the enzyme-catalyzed GSH and water additions at the $\mathrm{C} 1$ and $\mathrm{C} 2$ positions of fosfomycin. The calculations reproduce the experimentally observed regiospecificity, with GSH exclusively attacking C1 of fosfomycin. The competing water attack pathway is found to have a significantly higher barrier, in line with the observed chemoselectivity of this enzyme.

The uncatalyzed reaction was investigated using methanethiol as a model substrate for GSH with the assistance of two water molecules. The calculated barriers for attack at $\mathrm{C} 1$ and $\mathrm{C} 2$ are very close to each other, being around $29 \mathrm{kcal} / \mathrm{mol}$ at the B3LYP level, in good agreement with experimental kinetic results. For each attack mode, the reaction takes place via a single concerted transition state, and the phosphonate group of fosfomycin functions as a base to abstract a proton from the thiol group and as an acid to deliver a proton to the leaving oxyanion.

For the enzyme-catalyzed GSH attack, we find a sequential two-step mechanism in QM/MM calculations on the full solvated enzyme, with initial proton transfer from GSH to Tyr39, followed by nucleophilic attack concomitant with epoxide ring-opening. The second step is calculated to be rate-limiting, with barriers of $9.2 \mathrm{kcal} / \mathrm{mol}$ for $\mathrm{C} 1$ attack and $18.1 \mathrm{kcal} / \mathrm{mol}$ for $\mathrm{C} 2$ attack. The preference for $\mathrm{C} 1$ attack is fully consistent with the experiments, which yield only $\mathrm{C} 1$ product. The enzyme catalyzes the reaction by using Tyr39 as a base to deprotonate $\mathrm{GSH}$ to generate the nucleophile and by utilizing the $\mathrm{Mn}^{2+}$ ion to provide electrostatic stabilization for the leaving oxyanion through direct coordination. The $\mathrm{Mn}^{2+}$ ion is in the high-spin sextet state, in agreement with experimental EPR studies. A number of active-site residues are found to be important for catalysis. Thr9 helps stabilize the leaving oxyanion by hydrogen-bonding interactions. Lys90, Ser94, Tyr100, and Arg119 form hydrogen bonds to the phosphonate group of fosfomycin, which facilitate substrate binding and also shield the negative charge to alleviate electrostatic repulsion between the phosphonate and thiolate in the crucial transition state. A distortion/interaction analysis shows that the regioselectivity is mainly controlled by the different geometric distortion of fosfomycin in the competing transition states (imposed and partially stabilized by the activesite residues).

When a water molecule is used as a nucleophile, the reaction takes place in one single concerted step but has a significantly higher barrier than in the GSH case. The attack at $\mathrm{C} 2$ is preferred. The distortion of the transition state for water attack is associated with a larger energetic penalty than that for GSH attack, which accounts for the different ease of these two reactions.

\section{ASSOCIATED CONTENT}

\section{S Supporting Information}

Setup of the systems; CHARMM parameters; IRC profiles and coordinates for the uncatalyzed reaction; active regions for $\mathrm{QM} / \mathrm{MM}$ optimizations; $\mathrm{QM}, \mathrm{MM}$, and $\mathrm{QM} / \mathrm{MM}$ energies for all stationary points; optimized structures for M2a (GSH attack) and $\mathbf{M} \mathbf{2 b}$ (water attack); complete citations for refs 42 , 53, and 55. This material is available free of charge via the Internet at http://pubs.acs.org.

\section{AUTHOR INFORMATION}

\section{Corresponding Author}

*E-mail: thiel@kofo.mpg.de.

\section{Notes}

The authors declare no competing financial interest.

\section{ACKNOWLEDGMENTS}

This work was supported by the Max Planck Society and the Volkswagenstiftung.

\section{REFERENCES}

(1) Hendlin, D.; Stapley, E. O.; Jackson, M.; Wallick, H.; Miller, A. K.; Wolf, F. J.; Miller, T. W.; Chaiet, L.; Kahan, F. M.; Foltz, E. L.; et al. Science 1969, 166, 122-123.

(2) Christensen, B. G.; Leanza, W. J.; Beattie, T. R.; Patchett, A. A.; Arison, B. H.; Ormond, R. E.; Kuehl, F. A., Jr.; Albers-Schonberg, G.; Jardetzky, O. Science 1969, 166, 123-125.

(3) Kahan, F. M.; Kahan, J. S.; Cassidy, P. J.; Kropp, H. Ann. N.Y. Acad. Sci. 1974, 235, 364-386.

(4) Marquardt, J. L.; Brown, E. D.; Lane, W. S.; Haley, T. M.; Ichikawa, Y.; Wong, C.-H.; Walsh, C. T. Biochemistry 1994, 33, 10646-10651.

(5) Skarzynski, T.; Mistry, A.; Wonacott, A.; Hutchinson, S. E.; Kelly, V. A.; Duncan, K. Structure 1996, 4, 1465-1474.

(6) Arca, P.; Rico, M.; Braña, A. F.; Villar, C. J.; Hardisson, C.; Suárez, J. E. Antimicrob. Agents Chemother. 1988, 32, 1552-1556.

(7) Arca, P.; Hardisson, C.; Suárez, J. E. Antimicrob. Agents Chemother. 1990, 34, 844-848.

(8) Armstrong, R. N. Chem. Res. Toxicol. 1997, 10, 2-18.

(9) Bernat, B. A.; Laughlin, L. T.; Armstrong, R. N. Biochemistry 1997, 36, 3050-3055.

(10) Bernat, B. A.; Laughlin, L. T.; Armstrong, R. N. J. Org. Chem. 1998, 63, 3778-3780.

(11) Bernat, B. A.; Laughlin, L. T.; Armstrong, R. N. Biochemistry 1999, 38, 7462-7469.

(12) Bernat, B. A.; Armstrong, R. N. Biochemistry 2001, 40, 1271212718.

(13) Rife, C. L.; Pharris, R. E.; Newcomer, M. E.; Armstrong, R. N. J. Am. Chem. Soc. 2002, 124, 11001-11003.

(14) Cao, M.; Bernat, B. A.; Wang, Z.; Armstrong, R. N.; Helmann, J. D. J. Bacteriol. 2001, 183, 2380-2383.

(15) Fillgrove, K. L.; Pakhomova, S.; Newcomer, M. E.; Armstrong, R. N. J. Am. Chem. Soc. 2003, 125, 15730-15731.

(16) Fillgrove, K. L.; Pakhomova, S.; Schaab, M. R.; Newcomer, M. E.; Armstrong, R. N. Biochemistry 2007, 46, 8110-8120.

(17) Brown, D. W.; Schaab, M. R.; Birmngham, W. R.; Armstrong, R. N. Biochemistry 2009, 48, 1847-1849.

(18) Armstrong, R. N. Biochemistry 2000, 39, 13625-13632.

(19) Rigsby, R. E.; Rife, C. L.; Fillgrove, K. L.; Newcomer, M. E.; Armstrong, R. N. Biochemistry 2004, 43, 13666-13673.

(20) Pakhomova, S.; Rife, C. L.; Armstrong, R. N.; Newcomer, M. E. Protein Sci. 2004, 13, 1260-1265. 
(21) Smoukov, S. K.; Telser, J.; Bernat, B. A.; Rife, C. L.; Armstrong, R. N.; Hoffman, B. M. J. Am. Chem. Soc. 2002, 124, 2318-2326.

(22) Walsby, C. J.; Telser, J.; Rigsby, R. E.; Armstrong, R. N.; Hoffman, B. M. J. Am. Chem. Soc. 2005, 127, 8310-8319.

(23) Beharry, Z.; Palzkill, T. J. Biol. Chem. 2005, 280, 17786-17791.

(24) Rigsby, R. E.; Brown, D. W.; Dawson, E.; Lybrand, T. P.; Armstrong, R. N. Arch. Biochem. Biophys. 2007, 464, 277-283.

(25) Nardini, M.; Ridder, I. S.; Rozeboom, H. J.; Kalk, K. H.; Rink, R.; Janssen, D. B.; Dijkstra, B. W. J. Biol. Chem. 1999, 274, 1457914586 .

(26) Argiriadi, M. A.; Morisseau, C.; Goodrow, M. H.; Dowdy, D. L.; Hammock, B. D.; Christianson, D. W. J. Biol. Chem. 1999, 275, 15265-15270.

(27) Argiriadi, M. A.; Morisseau, C.; Hammock, B. D.; Christianson, D. W. Proc. Natl. Acad. Sci. U.S.A. 1999, 96, 10637-10642.

(28) Zou, J.; Hallberg, B. M.; Bergfors, T.; Oesch, F.; Arand, M.; Mowbray, S. L.; Jones, T. A. Structure 2000, 8, 111-122.

(29) van Hylckama Vlieg, J. E. T.; Tang, L.; Lutje Spelberg, J. H.; Smilda, T.; Poelarends, G. J.; Bosma, T.; van Merode, A. E.; Fraaije, M. W.; Janssen, D. B. J. Bacteriol. 2001, 183, 5058-5066.

(30) de Jong, R. M.; Tiesinga, J. J. W.; Rozeboom, H. J.; Kalk, K. H.; Tang, L.; Janssen, D. B.; Dijkstra, B. W. EMBO J. 2003, 22, 49334944.

(31) Mitra, S.; Holz, R. C. J. Biol. Chem. 2007, 282, 7397-7404.

(32) Sun, S.; Toney, M. D. Biochemistry 1999, 38, 4058-4065.

(33) Roszak, A. W.; Robinson, D. A.; Krell, T.; Hunter, I. S.; Fredrickson, M.; Abell, C.; Coggins, J. R.; Lapthorn, A. J. Structure 2002, 10, 493-503.

(34) Yip, V. L. Y.; Withers, S. G. Biochemistry 2012, 51, 8464-8474.

(35) Lau, E. Y.; Newby, Z. E.; Bruice, T. C. J. Am. Chem. Soc. 2001, 123, 3350-3357.

(36) Hopmann, K. H.; Hallberg, B. M.; Himo, F. J. Am. Chem. Soc. 2005, 127, 14339-14347.

(37) Hopmann, K. H.; Himo, F. Chem.-Eur. J. 2006, 12, 68986909

(38) Hopmann, K. H.; Himo, F. J. Phys. Chem. B 2006, 110, 2129921310.

(39) Hopmann, K. H.; Himo, F. Biochemistry 2008, 47, 4973-4982.

(40) Lonsdale, R.; Hoyle, S.; Grey, D. T.; Ridder, L.; Mulholland, A. J. Biochemistry 2012, 51, 1774-1786.

(41) Hou, Q. Q.; Sheng, X.; Wang, J. H.; Liu, Y. J.; Liu, C. B. Biochim. Biophys. Acta 2012, 1824, 263-268.

(42) Frisch, M. J.; Trucks, G. W.; Schlegel, H. B.; Scuseria, G. E.; Robb, M. A.; Cheeseman, J. R.; Scalmani, G.; Barone, V.; Mennucci, B.; Petersson, G. A. et al. Gaussian 09, revision B.01; Gaussian, Inc.: Wallingford, CT, 2009.

(43) Becke, A. D. J. Chem. Phys. 1993, 98, 5648-5652.

(44) Weigend, F.; Ahlrichs, R. Phys. Chem. Chem. Phys. 2005, 7, 3297-3305.

(45) Gonzalez, C.; Schlegel, H. B. J. Chem. Phys. 1989, 90, 21542161.

(46) Gonzalez, C.; Schlegel, H. B. J. Phys. Chem. 1990, 94, 55235527.

(47) Marenich, A. V.; Cramer, C. J.; Truhlar, D. G. J. Phys. Chem. B 2009, 113, 6378-6396.

(48) Zhao, Y.; Truhlar, D. G. Theor. Chem. Acc. 2008, 120, 215-241.

(49) Chai, J. D.; Head-Gordon, M. J. Chem. Phys. 2008, 128, 084106.

(50) Grimme, S. J. Chem. Phys. 2006, 124, 034108.

(51) Olsson, M. H. M.; Søndergaard, C. R.; Rostkowski, M.; Jensen,

J. H. J. Chem. Theory Comput. 2011, 7, 525-537.

(52) Trott, O.; Olson, A. J. J. Comput. Chem. 2010, 31, 455-461.

(53) MacKerell, A. D., Jr.; Bashford, D.; Bellott, M.; Dunbrack, R. L., Jr.; Evanseck, J.; Field, M. J.; Fischer, S.; Gao, J.; Guo, H.; Ha, S.; et al. J. Phys. Chem. B 1998, 102, 3586-3616.

(54) Brooks, B. R.; Bruccoleri, R. E.; Olafson, B. D.; States, D. J.; Swaminathan, S.; Karplus, M. J. Comput. Chem. 1983, 4, 187-217.

(55) Sherwood, P.; de Vries, A. H.; Guest, M. F.; Schreckenbach, G.; Catlow, C. R. A.; French, S. A.; Sokol, A. A.; Bromley, S. T.; Thiel, W.; Turner, A. J.; et al. J. Mol. Struct. (THEOCHEM) 2003, 632, 1-28.
(56) Chemshell, a Computational Chemistry Shell; Science \& Technology Facilities Council: Swindon, U.K.; www.chemshell.org (accessed on December 12, 2012).

(57) Ahlrichs, R.; Bär, M.; Häser, M.; Horn, H.; Kölmel, C. Chem. Phys. Lett. 1989, 162, 165-169.

(58) Smith, W.; Forester, T. R. J. Mol. Graphics 1996, 14, 136-141.

(59) Grimme, S. J. Comput. Chem. 2006, 27, 1787-1799.

(60) Baker, J. J. Comput. Chem. 1986, 7, 385-395.

(61) Bundgaard, H. Int. J. Pharm. 1980, 6, 1-9.

(62) Baillet, A.; Pianetti, G. A.; Taverna, M.; Mahuzier, G.; BaylocqFerrier, D. J. Chromatogr. 1993, 616, 311-316.

(63) Cox, H.; Akibo-Betts, G.; Wright, R. R.; Walker, N. R.; Curtis, S.; Duncombe, B.; Stace, A. J. J. Am. Chem. Soc. 2003, 125, 233-242.

(64) Lundberg, M.; Siegbahn, P. E. M. J. Comput. Chem. 2005, 26, 661-667.

(65) Khodabandeh, M. H.; Davari, M. D.; Zahedi, M.; Ohanessian, G. Int. J. Mass Spectrom. 2010, 291, 73-83.

(66) Musgrave, R. A.; Turbervill, R. S. P.; Irwin, M.; Goicoechea, J. M. Angew. Chem., Int. Ed. 2012, 51, 10832-10835.

(67) Ess, D. H.; Houk, K. N. J. Am. Chem. Soc. 2008, 130, 1018710198.

(68) Schoenebeck, F.; Houk, K. N. J. Am. Chem. Soc. 2010, 132, 2496-2497.

(69) Liu, P.; McCarren, P.; Cheong, P. H. Y.; Jamison, T. F.; Houk, K. N. J. Am. Chem. Soc. 2010, 132, 2050-2057.

(70) Potavathri, S.; Pereira, K. C.; Gorelsky, S.; Pike, A.; LeBris, A. P.; DeBoef, B. J. Am. Chem. Soc. 2010, 132, 14676-14681.

(71) Gorelsky, S. I.; Lapointe, D.; Fagnou, K. J. Org. Chem. 2012, 77, $658-668$.

(72) Mladenovic, M.; Junold, K.; Fink, R. F.; Thiel, W.; Schirmeister, T.; Engels, B. J. Phys. Chem. B 2008, 112, 5458-5469.

(73) Mladenovic, M.; Ansorg, K.; Fink, R. F.; Thiel, W.; Schirmeister, T.; Engels, B. J. Phys. Chem. B 2008, 112, 11798-11808.

(74) Strajbl, M.; Florián, J.; Warshel, A. Int. J. Quantum Chem. 2000, $77,44-53$.

(75) Arantes, G. M.; Chaimovich, H. J. Phys. Chem. A 2005, 109, $5625-5635$. 